\title{
Effects of chocolate milk consumption on markers of muscle recovery following soccer training: a randomized cross-over study
}

\author{
Stephanie F Gilson'1, Michael J Saunders*1, Charles W Moran'1, Rebecca W Moore², Christopher J Womack and M \\ Kent Todd 1
}

\begin{abstract}
Background: The efficacy of chocolate milk (CM) as a recovery beverage following a period of increased training duration (ITD) was studied in intercollegiate soccer players.

Methods: 13 subjects completed one week of normal 'baseline' training followed by four days of ITD. After each day of ITD, subjects received either a high-carbohydrate (504 kcal; CHO: $122 \mathrm{~g} ; 2 \mathrm{~g}$ Fat) or isocaloric CM (504 kcal; $84 \mathrm{~g} \mathrm{CHO;} 28$ $\mathrm{g}$ Pro; $7 \mathrm{~g}$ Fat) recovery beverage. Serum creatine kinase (CK), myoglobin (Mb), muscle soreness, fatigue ratings and isometric quadriceps force (MVC) were obtained prior to ITD, and following 2- and 4-days of ITD. Performance tests (Tdrill, vertical jump) were performed within training sessions. Treatments were administered in a randomly counterbalanced protocol, and subjects repeated the procedures with the alternate beverage following a two-week washout period.

Results: Mean daily training time and HR increased $(p<0.05)$ between baseline training and ITD, with no differences between treatments. No treatment*time effects were observed for Mb, muscle soreness, fatigue ratings and MVC. However, serum CK was significantly lower $(p<0.05)$ following four days of ITD with CM (316.9 \pm 188.3 U.L L-1) compared to $\mathrm{CHO}\left(431.6 \pm 310.8 \mathrm{U} \cdot \mathrm{L}^{-1}\right)$. No treatment differences were observed for the performance tests.

Conclusions: Post-exercise CM provided similar muscle recovery responses to an isocaloric $\mathrm{CHO}$ beverage during fourdays of ITD. Future studies should investigate if the attenuated CK levels observed with CM have functional significance during more demanding periods of training.
\end{abstract}

\section{Background}

The timing and composition of nutrient intake can significantly influence recovery from heavy exercise (i.e. [1$10])$. Increased carbohydrate intake immediately following exercise results in faster rates of muscle glycogen replenishment [1,2] and can attenuate symptoms of overreaching during periods of intensified endurance training, such as negative mood states, increased perceived exertion, and impaired performance [3]. The addition of protein to post-exercise carbohydrate feedings can also influence recovery from heavy exercise. Carbohydrate and protein $(\mathrm{CHO}+\mathrm{Pro})$ supplementation has been

\footnotetext{
* Correspondence: saundemj@jmu.edu

1 Department of Kinesiology, MSC 2302, James Madison University, Harrisonburg, VA 22807, USA

Full list of author information is available at the end of the article
}

shown to attenuate markers of sarcolemmal disruption, such as creatine kinase (CK) and myoglobin [4-10], reduce muscle soreness $[6,7,11]$ and improve subsequent muscle function $[5,10]$ compared to carbohydrate-only beverages, though not all studies have reported these effects [11-13]. In addition, $\mathrm{CHO}+$ Pro ingestion during recovery from heavy exercise has been shown to improve performance in subsequent whole-body exercise in some [9,14-18], but not all studies [6-8,11,19-21].

Chocolate milk (CM) has been investigated recently as a potential recovery beverage, as it contains carbohydrate and protein in similar amounts to $\mathrm{CHO}+$ Pro beverages associated with improved post-exercise recovery. In addition, CM has been noted for its' good taste, wide availability, low cost and convenience, which could make it a popular alternative to commercial sports beverages. Two 
studies reported that $\mathrm{CM}$ consumption following a heavy endurance exercise session was associated with equal [22] or superior [23] performance during subsequent exercise compared to carbohydrate alone. Similarly, Cockburn et al. [5] reported that compared to carbohydrate beverages, $\mathrm{CM}$ ingestion during recovery from heavy eccentric exercise improved peak torque and total work during subsequent exercise. However, the carbohydrate beverages utilized in each of these studies contained fewer calories than CM, so it is possible that the purported benefits may have been related to caloric differences between treatments.

At least two studies have examined $\mathrm{CHO}+$ Pro ingestion in free-living endurance athletes. Luden et al. [6] reported that $\mathrm{CHO}+$ Pro attenuated plasma $\mathrm{CK}$ and muscle soreness compared to $\mathrm{CHO}$ in collegiate distance runners during six days of training. Similarly, Cade et al. [24] reported improvements in plasma CK and lactate dehydrogenase with $\mathrm{CHO}+$ Pro supplementation during intensive training in collegiate swimmers. However, we are aware of no studies comparing $\mathrm{CHO}$ and $\mathrm{CHO}+$ Pro treatments on recovery in team-sport athletes such as soccer players. Soccer is an alternating-intensity endurance sport which has been shown to significantly reduce muscle glycogen stores $[25,26]$. In addition, plyometric exercises such as those utilized in soccer training have been associated with increased muscle soreness, elevated blood CK levels and impaired performance in subsequent exercise [27]. Thus, the utilization of post-exercise nutrition interventions that influence these variables could potentially affect recovery in soccer players. The purpose of this study was to compare the effects of CM to an isocaloric carbohydrate beverage on markers of recovery following a period of increased training duration in competitive soccer players.

\section{Methods Participants}

Twenty-two NCAA Division I male soccer players volunteered for the study following a complete explanation of procedures. Five subjects failed to complete all testing, or were unable to complete consistent training programs due to musculoskeletal injuries unrelated to the study. Four subjects were excluded from final statistical analyses due to large variations in dependent measurements between baseline periods (described below) resulting in 13 subjects included in data analyses. Prior to the study, all potential subjects signed an informed consent form and completed a Pre-participation Screening Questionnaire [28]. Individuals with preexisting injury, those taking medications to relieve soreness, or with milk allergies were excluded from study participation. All procedures were approved by the JMU Institutional Review Board prior to initiation of the study.

A minimum of 12 participants were recruited for the present study, in order to detect potential between-treatment differences of 1.2-1.6 SD units with a $\beta>0.80$. This sample size was estimated using calculations from Lipsey [29], and utilized effect-sizes reported in previous studies comparing the effects of $\mathrm{CHO}+$ Pro and $\mathrm{CHO}$ beverages on the dependent measures utilized in this study (i.e. $[7,9,10])$. For example, using mean values reported by Valentine et al. [10], $\mathrm{CHO}+$ Pro ingestion produced an effect on post-exercise plasma CK values of approximately 1.6 SD units, assuming a correlation of 0.80 between repeated measurements [29].

\section{Training Protocols}

All testing was conducted during the athletes' off-season training period. On two occasions, subjects performed one week of normal 'baseline' training, followed immediately by four days of increased training duration (ITD). Baseline training levels represented typical training types/amounts conducted by the team during off-season training. The ITD period was intended to increase total training duration by $>25 \%$ during four consecutive days of training. The number of days of ITD (and daily training times) were selected to produce a practically-relevant increase in training demands, without violating NCAA regulations limiting Division I athletes outside of the playing season to a maximum of $8 \mathrm{hr}$ of athleticallyrelated activities per week (NCAA Playing and Practice Limitations, Bylaw 17.1.5.2).

Daily training sessions (Mon-Fri) consisted of alternating days of a) soccer-specific training drills and aerobic development activities, and $\mathrm{b}$ ) strength and sprint training (Table 1). On Mon/Wed/Fri, the prescribed training sessions consisted of a) warm-up ( 10 min), b) agility drills ( 10 min), c) main training session, and d) cool down ( 10 min). The length of the main training segment on these days varied from 60-90 min (depending on whether it occurred during baseline or ITD), and included soccer-specific training drills and game-play, with a heavy aerobic conditioning component. On Tu/Th the prescribed training consisted of a) warm-up ( 10 min), b) main training session, and c) cool down ( 10 $\mathrm{min})$. The main training session on these days included sprint/plyometric training drills (such as 'ladder footwork', standardized agility runs and coordination drills), followed by resistance training exercises. The length of the main training segment varied from $55-70 \mathrm{~min}$ on these days (baseline or ITD). Sprint/plyometric exercises and resistance training comprised an equal portion of the main training session on these days. No organized training sessions were conducted for two days prior to the ITD 


\begin{tabular}{|c|c|c|c|}
\hline \multirow[b]{2}{*}{ Day of Training } & \multirow[b]{2}{*}{ Training Type } & \multicolumn{2}{|c|}{ Length of Session } \\
\hline & & $\begin{array}{l}\text { Week 1: } \\
\text { Baseline }\end{array}$ & $\begin{array}{l}\text { Week 2: } \\
\text { ITD }\end{array}$ \\
\hline Mon & $\begin{array}{l}\text { Soccer-specific training drills } \\
\text { and aerobic development }\end{array}$ & $90 \mathrm{~min}$ & $120 \mathrm{~min}$ \\
\hline Tues & Strength and sprint training & $75 \mathrm{~min}$ & $90 \mathrm{~min}$ \\
\hline Wed & $\begin{array}{l}\text { Soccer-specific training drills } \\
\text { and aerobic development }\end{array}$ & $90 \mathrm{~min}$ & $120 \mathrm{~min}$ \\
\hline Thurs & Strength and sprint training & $75 \mathrm{~min}$ & $90 \mathrm{~min}$ \\
\hline Fri & $\begin{array}{l}\text { Soccer-specific training drills } \\
\text { and aerobic development }\end{array}$ & $90 \mathrm{~min}$ & $\mathrm{~N} / \mathrm{A}$ \\
\hline Sat & $\begin{array}{l}\text { Low-intensity aerobic } \\
\text { recovery }\end{array}$ & $\begin{array}{c}\text { 30-45 min } \\
\text { (unsupervised) }\end{array}$ & $\mathrm{N} / \mathrm{A}$ \\
\hline Sun & $\begin{array}{l}\text { Low-intensity aerobic } \\
\text { recovery }\end{array}$ & $\begin{array}{c}\text { 30-45 min } \\
\text { (unsupervised) }\end{array}$ & $\mathrm{N} / \mathrm{A}$ \\
\hline
\end{tabular}

periods (Sat/Sun). Athletes were permitted to exercise on their own, but were instructed to limit exercise to a maximum of 30-45 minutes of low-intensity aerobic exercise (jogging).

Specific training exercises were prescribed to be virtually identical between the two treatment periods. Training variables were recorded throughout the exercise sessions to quantify exercise intensity, and to ensure consistency between training periods. Heart rate was obtained during all training sessions (but not recorded during resistance training exercises) using a Polar heartrate monitor (Brooklyn, NY). Average heart rate values for each training session were recorded. Ratings of perceived exertion (RPE) were obtained using the Borg RPE 6-20 scale immediately after each training session. Total exercise time was also recorded for each training session.

Participants completed all procedures on two occasions, with a two-week period of recovery and resumed training between the two study periods. A randomly counterbalanced design was utilized so that any changes in dependent measurements over time would be randomly distributed within each treatment period. Each training session was conducted by the teams' coaches, under the supervision of the investigators.

\section{Physiological Measurements}

The following measurements were obtained on Monday (Pre ITD), Wednesday (Post2), and Friday (Post4) of each ITD period. On these dates, subjects reported to the laboratory prior to the daily practice session, approximately 18-22 hours following the previous day's training session. The specific measurement time varied between subjects to accommodate individual schedules, but was scheduled at a consistent time over the course of the study for each subject. Measurements are listed below in the order in which they were obtained during testing sessions.

Muscle Soreness Ratings: Soreness ratings were obtained using a $100 \mathrm{~mm}$ visual analog scale, with 0 indicating no muscle soreness and 100 indicating impaired movement due to muscle soreness, as described previously [30]. Subjects were asked to describe their overall level of muscle soreness in the legs while performing normal daily activities such as walking up or down stairs.

Mental and Physical Fatigue Ratings: These ratings were obtained using Part II of the Mental and Physical State and Trait Energy and Fatigue Scales (MPSTEFS; P.J. O'Connor, personal communication). Separate ratings were obtained for Physical Energy, Physical Fatigue, Mental Energy and Mental Fatigue, on the basis of " how do you feel right now" instructions, as described by Kline et al. [31]. Each rating represented the combined scores from three visual analog scales of $0-100 \mathrm{~mm}$ (i.e. the total score for Physical Energy represented the combined scores of three scales which rated the participant's relative degree of "energy", "vigor" and "pep"). Thus, each of the four energy/fatigue ratings had potential scores varying from $0-300 \mathrm{~mm}$. Higher scores on this scale represented higher degrees of the variable (i.e. a higher "Mental Fatigue" score represented a higher degree of mental fatigue).

Serum Creatine Kinase (CK): Blood was obtained from an antecubital vein following completion of the muscle soreness and MPSTEFS questionnaires. Whole blood was spun in a centrifuge at $7000 \mathrm{rpm}$ to obtain serum, which was stored at $-80^{\circ} \mathrm{C}$, brought to room temperature $\left(22^{\circ} \mathrm{C}\right)$ prior to analysis, and mixed 
through gentle inversion. Serum CK was analyzed using a Johnson and Johnson Vitro DT 6011 analyzer, according to the manufacture's instructions. All samples were run in duplicate, and mean values were recorded.

Serum Myoglobin (Mb): Serum Mb levels were assessed using commercially available ELISA kits (BioCheck, Inc.) according to the manufacturer's instructions. A standard curve was prepared using reference standards ranging from 0 to $1,000 \mathrm{ng} / \mathrm{mL}$ $\mathrm{Mb}$. Absorbance of the 96-well assay plate was read at a wavelength of $450 \mathrm{~nm}$ using a microplate spectrophotometer. All samples were run in duplicate on the same assay plate and mean values recorded.

Maximal Voluntary Contraction (MVC): Voluntary isometric peak force of the right quadriceps was assessed using a custom-built muscle function device. All subjects performed the test in an upright seated position with the right leg positioned at approximately $70^{\circ}$ of knee flexion. Subjects provided a maximal $3 \mathrm{~s}$ leg extension against a stationary bar positioned at a standardized position on the shin. The right leg was used for all subjects (as opposed to dominant leg) to insure identical positioning of the shin against the stationary bar. Force measurements were obtained from a force transducer throughout each contraction, and peak force was obtained from each trial using custom designed software. Subjects performed three maximum voluntary contractions, with 1 min rest between trials. Peak force was recorded as the highest value from the three trials. Using the same testing protocols, we have previously observed a coefficient of variation (CV) of $6.9 \%$ between repeated trials performed under similar exercise conditions (i.e. male athletes tested prior to exercise with repeated trials separated by $\sim 1$ week).

\section{Table 2: Comparison of Beverage Ingredients}

\begin{tabular}{lcc}
\hline Nutrient & CM & CHO \\
\hline Volume $(\mathrm{mL})$ & 672 & 672 \\
Energy $(\mathrm{kcal})$ & 504 & 504 \\
Carbohydrate $(\mathrm{g})$ & 84 & 122 \\
Protein $(\mathrm{g})$ & 28 & 0 \\
Fat $(\mathrm{g})$ & 7 & 2 \\
Sodium $(\mathrm{mg})$ & 511 & 277 \\
Potassium $(\mathrm{mg})$ & 0 & 202 \\
Vitamin C $(\mathrm{mg})$ & 7 & 302 \\
Vitamin E $(\mathrm{mg})$ & 0 & 101 \\
Calcium $(\mathrm{mg})$ & 852 & 101 \\
\hline
\end{tabular}

\section{Performance Measurements}

The following soccer-specific tests of performance were conducted on the dates indicated during the ITD periods.

Modified pro-agility test (T-drill): The test consisted of four directional changes ( 2 of 90 degrees, 2 of 180 degrees) in a 40 meter sprint test [32]. The test was completed on a grass field on Tuesday of the ITD periods, immediately prior to the start of strength training. Three testers recorded time to completion using manual digital stopwatches. Inter-tester variability was very low between these measurements $(\mathrm{CV}<1 \%)$. The average of the three times was recorded for each trial. Each subject completed the test twice and the fastest trial time was recorded.

Vertical jump test: The test was performed on Friday of the ITD period. Subjects completed three vertical jumps, measured using a $\operatorname{Vertec}^{\mathrm{Tm}}$ vertical jump assessment device with 0.5 inch increments. Countermovement jumps were performed for all trials, as described by Byrne and Eston [33]. Subjects were permitted to utilize their arms in the movement. The highest jump height of the three trials was recorded for each subject.

\section{Treatments and Dietary Controls}

Immediately following each training session of the ITD period, subjects consumed one of two recovery treatment beverages described below. Specific treatments were assigned to the subjects using a randomly-counterbalanced design. Beverages were consumed within 5 minutes of completion of each exercise session.

Low-Fat Chocolate Milk Beverage (CM): Each serving consisted of $672 \mathrm{ml}$ of $\mathrm{CM}$, containing $84 \mathrm{~g} \mathrm{CHO}, 28 \mathrm{~g}$ protein, $7 \mathrm{~g}$ fat, and approximately 504 total kcal (Table 2). Thus, each serving provided approximately $1.1 \mathrm{~g} \mathrm{CHO}^{\mathrm{kgBW}} \mathrm{gW}^{-1}$, which approximates levels associated with optimal recovery of muscle glycogen [34,35].

Carbohydrate Beverage $(\mathrm{CHO})$ : Each serving provided $672 \mathrm{ml}$ of an $18.6 \%$ carbohydrate beverage ( 1.5 $\mathrm{g} \mathrm{CHO} \mathrm{kgBW}^{-1}$ ), providing $122 \mathrm{~g} \mathrm{CHO}, 0 \mathrm{~g}$ protein, 2 $\mathrm{g}$ fat, and approximately 504 total kcal (Table 2). Chocolate-flavored commercially-available carbohydrate gels (Clif Shots') were mixed with water to provide similar taste and color to the CM beverage.

Subjects were assigned their beverage treatment order by a laboratory assistant who was not directly involved in the study, via a coin-flip. Once half of the participants had been assigned one of the beverages for their first treatment period (either $\mathrm{CM}$ or $\mathrm{CHO}$ ), any remaining subjects were assigned the alternative beverage, to insure a counterbalanced allocation of treatments. Beverage preparation and labelling was conducted by an investigator who did not participate in the data collection process. 
Researchers were not aware which beverages the subjects were receiving until the study was completed. Similarly, the subjects were not informed of the composition of the beverages until cessation of the study. Anecdotal reports from subjects following the study suggest that subjects were aware of differences in taste between the beverages, but had no preconceived notions regarding differing ingredients or perceived efficacy. However, no systematic data was collected regarding subject perceptions of the beverages.

Subjects were instructed not to consume any other nutrients for 2-hours following each training session. Subjects were not required to adjust their regular diets (other than the post-exercise treatments they received), but were encouraged to replicate the same dietary habits during the two treatment periods. Dietary records were obtained for the four-day ITD period, and analyzed by FoodWise software (McGraw-Hill Science/Engineering/ Math, 2005) for total caloric, protein, and fat intake during the periods of increased training volume.

\section{Statistical Analysis}

Statistical testing was conducted using SPSS version 17.0 (Thomson Learning, Pacific Grove, CA), using an alpha level of $\mathrm{p}<0.05$ for all analyses. Training variables (average daily training time, heart rate and RPE) were analyzed using Repeated Measures Analysis of Variance (RMANOVA), with treatment (CM, CHO) and training period (baseline, ITD) as within-subject factors. Vertical jump performance and nutrient intake (carbohydrate, protein, fat) were compared between treatment periods using dependent $\mathrm{t}$-tests. $\mathrm{T}$-drill performance data was not normally distributed, and was therefore analyzed between treatments using a (non-parametric) Wilcoxon Signed Ranks test.

Most of the recovery variables (muscle soreness, MVC and all MPSTEFS ratings) were analyzed using RMANOVA, with treatment (CM, CHO) and time (PreITD, Post2, Post4) as within-subject factors. Post-hoc tests were conducted (where appropriate) to assess differences between individual time-points, with Bonferroni adjustments for multiple comparisons. Data for $\mathrm{CK}$ and $\mathrm{Mb}$ were not normally distributed, and thus were analyzed between treatments (at each time-point) using Wilcoxon Signed Ranks tests. Adjustments were made for multiple comparisons by dividing the alpha level by the number of comparisons for each variable.

Preliminary statistical analyses were performed on 17 subjects who completed all testing. However, some subjects exhibited large variances in baseline (PreITD) measurements between the two treatment periods, possibly due to activities outside of the study during the two unsupervised days prior to PreITD. This resulted in significant group differences in numerous PreITD measurements. In order to simplify interpretation of the hypothesis tests, absolute criteria were established to identify and remove individual subjects who exhibited large differences in PreITD values. These criteria were established using natural breaks in the score distributions. Four subjects exceeded the established criterion scores, and were thus eliminated from further statistical analyses. The exclusion criteria had the intended effect of eliminating all significant differences in PreITD values between treatments, making interpretation of the data simpler. However, it should be noted that exclusion of these subjects did not alter the outcomes of any hypothesis testing (i.e. any significant between-treatment outcomes reported in this manuscript were also significant with the entire group of 17 subjects).

\section{Results}

\section{Participants}

Statistical analyses were conducted on data from 13 collegiate NCAA Division I male soccer players. Average $( \pm$ SEM) age, height and weight of the participants were 19.5 $\pm 0.3 \mathrm{y}, 1.84 \pm 0.02 \mathrm{~m}$, and $79.4 \pm 2.6 \mathrm{~kg}$, respectively.

\section{Training Periods}

Data obtained from the training sessions are provided in Table 3. Average daily training time and heart rate were significantly increased $(\mathrm{p}<0.05)$ between the baseline and ITD periods. No differences in average training time, RPE or HR were observed between CHO and CM treatment periods. In addition, no significant differences ( $\mathrm{p}>$ 0.05 ) in dietary intake (kcal, carbohydrate, protein, fat) were observed between training periods (data not shown, as only seven subjects provided complete records for both training periods).

\section{Recovery Variables \& Performance Tests}

The effects of ITD and supplementation (CHO and $\mathrm{CM})$ on recovery variables are included in Table 4 and Figures 1 \&2. No significant treatment"time interactions were observed for any of the RM-ANOVA analyses (muscle soreness, MVC, MPSTEFS ratings). Significant $(\mathrm{p}<0.05)$ main-effects for time were observed for muscle soreness and MVC. Serum CK levels rose significantly following PreITD, and CK was significantly different between treatments at the Post4 time-point (Figure 1). No significant between-treatment differences were observed for other recovery variables. Data from the soccer-specific performance tests are shown in Table 5. No significant differences were observed between treatment periods.

\section{Discussion}

Training programs for competitive soccer players include activities of varying intensities, which have been shown to deplete muscle glycogen stores [25,26]. In addition, plyometric exercises such as vertical jumping, which are a 
Table 3: Daily Averages in Training Data

\begin{tabular}{ccc}
\hline Baseline Training Period & CHO & CM \\
\hline Time (min) & $85.1 \pm 1.4$ & $85.5 \pm 1.4$ \\
RPE (6-20) & $13.7 \pm 0.3$ & $13.8 \pm 0.2$ \\
HR (bt/min) & $143 \pm 3.4$ & $141 \pm 3.3$ \\
\hline
\end{tabular}

\begin{tabular}{|c|c|c|}
\hline \multicolumn{3}{|c|}{ Increased Training Duration } \\
\hline Time $^{*}(\min )$ & $95.5 \pm 3.0$ & $95.2 \pm 1.4$ \\
\hline RPE (6-20) & $14.3 \pm 0.4$ & $13.8 \pm 0.5$ \\
\hline $\mathrm{HR}^{*}(\mathrm{bt} / \mathrm{min})$ & $147 \pm 3.0$ & $143 \pm 3.0$ \\
\hline
\end{tabular}

Data reported are Mean \pm SEM, averaged for Monday through Thursday of each training week. ${ }^{*}=$ Significantly greater than baseline $(p<$ $0.05)$

common component of soccer training, have been associated with increased muscle soreness, elevated blood CK levels and impaired performance in subsequent exercise [27]. Thus, the utilization of post-exercise nutrition interventions that influence these variables could potentially affect recovery in soccer players. The purpose of this investigation was to assess the efficacy of $\mathrm{CM}$ as a post-

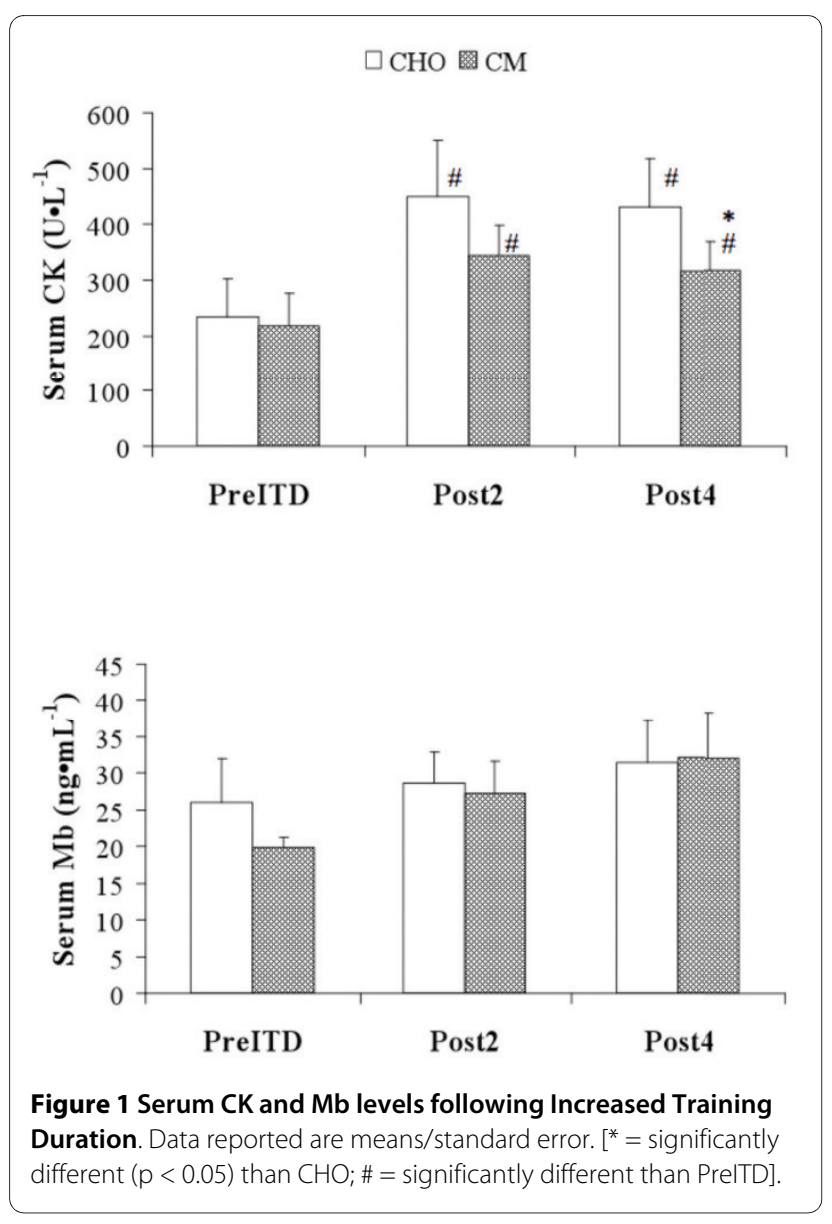

exercise recovery beverage in soccer players, compared to a carbohydrate-only beverage. The recovery drinks were matched in total caloric content (504 kcal/serving), and both beverages contained carbohydrate in amounts that approached (CM: $1.1 \mathrm{~g} / \mathrm{kg}$ ) or exceeded ( CHO: $1.5 \mathrm{~g} / \mathrm{kg}$ ) levels associated with optimal post-exercise glycogen repletion [34,35]. Although few studies have investigated the specific effects of CM on post-exercise recovery, our findings can also be compared with studies investigating $\mathrm{CHO}+$ Pro recovery beverages, which contain carbohydrate and protein in similar proportions to CM.

Overall, the isocaloric $\mathrm{CM}$ and $\mathrm{CHO}$ supplements provided similar effects on markers of post-exercise recovery over the four-day period of ITD. No significant treatment*time interactions were observed for muscle soreness, ratings of energy/fatigue and muscle function (MVC). Similarly, there were no treatment effects on serum $\mathrm{Mb}$. However, serum CK levels were significantly lower following four days of ITD with CM supplementation versus $\mathrm{CHO}$ supplementation. Numerous studies of

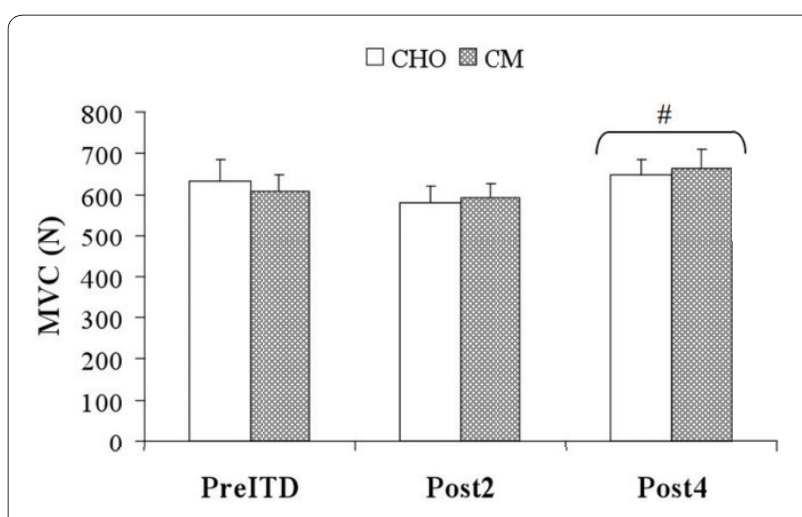

Figure 2 MVC levels following Increased Training Duration. Data reported are means/standard error. [\# = significantly different $(p<0.05)$ than PrelTD]. 
Table 4: Subjective Ratings of Muscle Soreness and Energy/Fatigue following Increased Training Duration

\begin{tabular}{|c|c|c|c|c|}
\hline \multirow[b]{2}{*}{ Recovery Variable } & \multirow[b]{2}{*}{ Treatment } & \multicolumn{3}{|c|}{ Timepoint } \\
\hline & & Pre-ITD & Post2 & Post4 \\
\hline \multirow{2}{*}{$\begin{array}{l}\text { Muscle Soreness*\# } \\
(\mathrm{mm})\end{array}$} & $\mathrm{CHO}$ & $43.2 \pm 6.7$ & $41.3 \pm 6.3$ & $48.8 \pm 8.0$ \\
\hline & $\mathrm{CM}$ & $34.9 \pm 6.4$ & $37.3 \pm 5.7$ & $45.3 \pm 7.5$ \\
\hline \multirow{2}{*}{$\begin{array}{l}\text { Physical Energy } \\
(\mathrm{mm})\end{array}$} & $\mathrm{CHO}$ & $171.4 \pm 14.8$ & $178.6 \pm 16.0$ & $158.3 \pm 19.1$ \\
\hline & $\mathrm{CM}$ & $162.6 \pm 15.6$ & $170.3 \pm 19.0$ & $166.7 \pm 18.5$ \\
\hline \multirow{2}{*}{$\begin{array}{l}\text { Physical Fatigue } \\
(\mathrm{mm})\end{array}$} & $\mathrm{CHO}$ & $133.3 \pm 12.5$ & $124.8 \pm 13.9$ & $115.8 \pm 17.6$ \\
\hline & $\mathrm{CM}$ & $114.2 \pm 13.5$ & $126.4 \pm 18.1$ & $132.8 \pm 19.5$ \\
\hline \multirow{2}{*}{$\begin{array}{l}\text { Mental Energy } \\
(\mathrm{mm})\end{array}$} & $\mathrm{CHO}$ & $177.9 \pm 12.9$ & $166.8 \pm 13.4$ & $166.4 \pm 19.4$ \\
\hline & $\mathrm{CM}$ & $172.4 \pm 17$ & $172.6 \pm 18.1$ & $164.3 \pm 20.0$ \\
\hline \multirow{2}{*}{$\begin{array}{l}\text { Mental Fatigue } \\
(\mathrm{mm})\end{array}$} & $\mathrm{CHO}$ & $135.8 \pm 15.6$ & $124.3 \pm 12.5$ & $125.8 \pm 18.4$ \\
\hline & $\mathrm{CM}$ & $119.6 \pm 16.4$ & $121.2 \pm 18.1$ & $138.6 \pm 19.8$ \\
\hline
\end{tabular}

$\mathrm{CHO}+$ Pro beverages have reported attenuated post-exercise plasma/serum CK levels after heavy endurance or resistance exercise [4,5,7-10], though this finding has not be observed in all studies $[11,12]$. The reduced CK levels observed in this investigation is also consistent with Cade et al. [24] and Luden et al. [6], who reported lower plasma $\mathrm{CK}$ levels with $\mathrm{CHO}+$ Pro ingestion over the course of multiple days of training in free-living swimmers and runners, respectively. Our findings similarly suggest that CM may attenuate blood CK levels in athletes performing heavy soccer training.

Plasma/serum CK is often used as a broad indicator of muscle damage. However, CK levels can be poorly correlated with direct measures of muscle damage or muscle function [36,37]. Thus, the practical significance of modestly lower serum CK levels $(\sim 115 \mathrm{U} / \mathrm{L})$ with $\mathrm{CM}$ is not clear. This is particularly notable here because other measures of recovery, such as muscle soreness and $\mathrm{Mb}$ were not significantly different between treatments. Findings from other studies have reported mixed findings with respect to the influence of $\mathrm{CHO}+$ Pro on these variables. Some have reported attenuated muscle soreness ratings or $\mathrm{Mb}$ levels following heavy endurance [6-8,10,11] or resistance exercise $[4,38]$, while others have reported no differences between treatments [12].

Though it cannot be concluded that recovery was different between treatments based on the CK data alone, other information from this study could suggest a potential tendency towards augmented recovery with CM. For example, increases in MVC over the four days of ITD were slightly greater with $\mathrm{CM}$ ingestion $(53 \pm 75 \mathrm{~N})$ than with $\mathrm{CHO}(16 \pm 93 \mathrm{~N})$. This observation is consistent

Table 5: Performance Tests

\begin{tabular}{lrr}
\hline Performance Test & CHO & Treatment Period \\
& & \\
\hline T-Drill (s) & $9.09 \pm 0.13$ & $9.06 \pm 0.16$ \\
Vertical Jump (inches) & $26.7 \pm 1.0$ & $26.7 \pm 1.0$ \\
\hline
\end{tabular}


with findings from Valentine et al. [10], who reported that $\mathrm{CHO}+$ Pro ingestion improved muscle function versus $\mathrm{CHO}$ and placebo beverages following heavy endurance exercise. The difference in MVC levels between treatments in the present study was not statistically significant ( $\mathrm{p}=0.295$ ), but may warrant investigation in future studies in light of the relatively small effect of our ITD protocol on symptoms of overreaching, as discussed below.

From a functional perspective, the most important measure of 'recovery' for athletes is performance in subsequent exercise. Some recent investigations have reported that $\mathrm{CHO}+$ Pro co-ingestion during/following heavy endurance exercise may improve subsequent exercise performance versus $\mathrm{CHO}$ [9,14-18]. However, a similar number of studies have reported no differences in subsequent performance between $\mathrm{CHO}$ and $\mathrm{CHO}+$ Pro recovery beverages [6-8,11,19-21]. Subsequent exercise performance was not assessed in the present study, as it was not possible to perform repeated sport-specific exercise testing within each training period without interfering significantly with the prescribed training programs from the coaching staff. However, sport-specific exercise tests (T-drill, vertical jump) were conducted within the ITD periods, and compared between treatments. Performance test results were virtually identical between treatment periods, suggesting that post-exercise $\mathrm{CM}$ consumption did not have a preferential effect on shortduration, high-intensity whole-body exercise performance versus $\mathrm{CHO}$. Our findings suggest that isocaloric $\mathrm{CHO}$ and $\mathrm{CM}$ beverages provide similar effects on whole body exercise recovery during short periods of heavy soccer training.

Few studies have examined the specific effects of CM on recovery from heavy endurance-based exercise. Karp et al. [22] compared three recovery beverages consumed following a glycogen-depleting session of cycling intervals. In a time-to-exhaustion test performed four hours later, cyclists rode significantly longer with CM compared to a commercial $\mathrm{CHO}+$ Pro beverage, but had similar performances as compared to a commercial $\mathrm{CHO}$ beverage. These findings are difficult to interpret, as $\mathrm{CM}$ contained similar carbohydrate and protein amounts than the $\mathrm{CHO}+$ Pro beverage, but the $\mathrm{CHO}$ beverage contained no protein and less than half the carbohydrate and caloric content than CM. More recently, Thomas et al. [23] conducted a similar study, comparing isocaloric $\mathrm{CM}$ and $\mathrm{CHO}+$ Pro beverages and a $\mathrm{CHO}$ beverage comparable to that used by Karp et al. [22]. Time to exhaustion in the subsequent exercise bout was significantly longer with $\mathrm{CM}$ than either comparison beverage. Although the potential mechanisms for these findings are not clear, these studies support the potential efficacy of $\mathrm{CM}$ as a post-exercise recovery beverage following heavy endurance exercise.
The present study was designed to compare recovery beverages in free-living athletes within a collegiate team setting. Although this maximizes the generalizability of our findings for athletes, there were some relevant limitations to this design. Firstly, the free-living environment may have increased measurement error over the course of the study. Great care was taken throughout the study to insure that training/nutritional conditions were virtually identical between the two treatment periods. However, it is possible that activities outside the experimental protocols may have influenced the outcomes of the study. For example, four of the seventeen participants who completed the study were removed from statistical analyses (as described in Methods) due to large variations in baseline measurements (i.e. prior to ITD and beverage treatments), possibly due to activities outside of the study parameters. Six subjects failed to return completed dietary recall questionnaires, and thus we cannot be certain that nutrient intake did not vary between treatment periods for the entire sample. In addition, subjects were instructed to replicate the same dietary habits between treatment periods, but were not required to arrive at the laboratory in a fasted state. Thus, differences in nutrient timing between treatment periods could also have influenced some of the study outcomes.

Another limitation was the NCAA regulation limiting out-of-season practice time to a maximum of $8 \mathrm{hrs}$ per week of 'athletically related activities' (NCAA Playing and Practice Limitations, Bylaw 17.1.5.2). As a result, it was not possible to implement an ITD period greater than 4 days in the present study. The prescribed training program was designed to increase daily training time by $>25 \%$ per day between baseline and ITD periods (Table 1). However, due to adjustments in training plans to accommodate for inclement weather on two days (and maintain consistency between treatment periods), the ITD period increased daily training times by only $12 \%$ (Table 3). This training stimulus produced significant increases in muscle soreness ratings, and serum CK levels over the four-day period. However, MPSTEFS ratings and serum $\mathrm{Mb}$ were not significantly altered over time, and MVC actually improved over the four days of ITD. These findings suggest that the relatively modest increase in training volumes (combined with the daily consumption of post-exercise recovery beverages) may have been an inadequate stimulus to substantially impair muscle recovery. Without a relatively robust effect on these markers following exercise, it may be difficult to assess differences in recovery between treatments, especially with a relatively small sample of subjects, as described by Luden et al. [6]. This issue is particularly relevant with regards to our measurements of vertical jump performance. Byrne and Eston [33] reported that vertical jump performance declined to $90 \%$ of initial levels one day following muscle 
damaging exercise. However, their exercise protocol produced elevations in CK that were approximately 3-4 times greater than the present study. Because our vertical jump device assessed only 0.5 inch increments, our instrument potentially lacked the sensitivity to detect realistic changes in vertical jump height. Other investigators have reported significant decrements in physical performance, fatigue and/or muscle soreness following periods of ITD $[3,39]$. However, these studies provided 8-11 days of ITD (and relatively low post-exercise carbohydrate intake), which represented a much greater alteration in training stimulus than the present study. Thus, it may be worthwhile for future researchers to investigate the efficacy of CM during longer, more demanding periods of ITD.

Due to the practical restrictions of studying collegiate athletes, it was also not possible to add a placebo trial to the present study design. This prevented us from establishing the direct effects of the ITD period, independent of supplementation. Recovery beverages were provided immediately post-exercise, and both contained high doses of carbohydrate $(>1.1 \mathrm{~g} / \mathrm{kg})$. As a result, both beverages probably produced high rates of post-exercise glycogen resynthesis [40], and potentially sustained muscle recovery and performance levels to a greater degree than if inadequate carbohydrate were provided [3,39]. However, the relative efficacy of the 'control' beverage in this study $(\mathrm{CHO})$ cannot be quantified without a placebo trial for comparison.

\section{Conclusions}

In summary, post-exercise CM supplementation resulted in significantly lower serum CK levels following four days of heavy soccer training. However, other measurements of muscle recovery were generally similar between treatment beverages, and there were no differences in wholebody exercise performance between treatments. Thus, exercise recovery during short-term periods of heavy soccer training appears to be similar when isocaloric $\mathrm{CM}$ and $\mathrm{CHO}$ beverages are consumed post-exercise. It is possible that potential differences between treatments could be magnified by a greater training stimulus. Thus, it is recommended that future studies perform similar comparisons during training periods that involve greater increases in training volumes over longer periods of time.

\section{Competing interests}

MJS has served as a member of an advisory committee for the National Dairy Council, and has received fees and travel reimbursement for work related to this role.

\section{Authors' contributions}

SFG participated as the lead author and participated in study design, screening and recruitment, data collection, analysis and interpretation, and final draft of the manuscript. MJS, acting as senior thesis advisor, participated in study design, screening and recruitment, data collection, analysis and interpretation, and final draft of the manuscript. CWM participated in data collection, analysis and interpretation, and editing of the manuscript. RWM participated in data collection and interpretation, and editing of the manuscript. CJW, acting as a thesis advisor, assisted with study design, data analysis and interpretation, and editing of the manuscript. MKT, acting as a thesis advisor, assisted with study design, data analysis and interpretation, and editing of the manuscript. All authors have read and approved the final draft of this manuscript.

\section{Acknowledgements}

The authors are grateful to the athletes, coaches and trainers of the JMU Soccer team for their considerable assistance and cooperation with this project. We also wish to thank Adam Clawson and Dana Corriere for their assistance with data collection. This project was supported by a research grant from the National Dairy Council and National Fluid Milk Processor Promotion Board. The results of the present study do not constitute an endorsement of any product or companies by the investigators.

\section{Author Details}

1Department of Kinesiology, MSC 2302, James Madison University, Harrisonburg, VA 22807, USA and 2Department of Kinesiology, Michigan State University, 134 Intramural Sports Circle, East Lansing MI 48824-1034, USA

Received: 15 January 2010 Accepted: 18 May 2010

Published: 18 May 2010

\section{References}

1. Ivy JL, Katz AL, Cutler CL, Sherman WM, Coyle EF: Muscle glycogen synthesis after exercise: effect of time of carbohydrate ingestion. J App/ Physiol 1988, 64:1480-1485.

2. Ivy JL, Lee MC, Brozinick JT, Reed MJ: Muscle glycogen storage after different amounts of carbohydrate ingestion. J App/ Physiol 1988, 65:2018-23.

3. Halson S, Lancaster G, Achten J, Gleeson M, Jeukendrup AE: Effects of carbohydrate supplementation on performance and carbohydrate oxidation after intensified cycling training. J Appl Physio/ 2004, 97:1245-1253.

4. Baty JJ, Hwang H, Ding Z, Bernard JR, Wang B, Kwon B, Ivy JL: The effect of a carbohydrate and protein supplement on resistance exercise performance, hormonal response, and muscle damage. J Strength Cond Res 2007, 21:321-329.

5. Cockburn E, Hayes PR, French DN: Acute milk-based protein-CHO supplementation attenuates exercise-induced muscle damage. Appl Physiol Nutr Metab 2008, 33:775-83.

6. Luden ND, Saunders MJ, Todd MK: Post-exercise carbohydrate-proteinantioxidant ingestion decreases CK and muscle soreness in crosscountry runners. Int J Sport Nutr Exerc Metab 2007, 17:109-122.

7. Romano-Ely BC, Todd MK, Saunders MJ, St Laurent TG: Effects of an isocaloric carbohydrate-protein-antioxidant drink on cycling performance. Med Sci Sports Exerc 2006, 38:1608-1616.

8. Rowlands DS, Thorp RM, Rossler K, Graham DF, Rockell MJ: Effect of protein-rich feeding on recovery after intense exercise. Int J Sport Nutr Exerc Metab 2007, 17:521-43.

9. Saunders MJ, Kane MD, Todd MK: Effects of a carbohydrate-protein beverage on cycling endurance and muscle damage. Med Sci Sports Exerc 2004, 36:1233-1238.

10. Valentine RJ, Saunders MJ, Todd MK, St Laurent TG: Influence of carbohydrate-protein beverage on cycling endurance and indices of muscle disruption. Int J Sport Nutr Exerc Metab 2008, 18:363-378.

11. Millard-Stafford M, Warren G, Thomas L, Doyle J, Snow T, Hitchcock K: Recovery from run training: efficacy of a carbohydrate-protein beverage? Int J Sport Nutr Exerc Metab 2005, 15:610-624.

12. Green MS, Corona BT, Doyle JA, Ingalls CP: Carbohydrate protein drinks do not enhance recovery from exercise-induced muscle injury. Int J Sport Nutr Exerc Metab 2008, 18:1-18.

13. Wojcik JR, Walberg-Rankin J, Smith LL, Gwazdauskas FC: Comparison of carbohydrate and milk-based beverages on muscle damage and glycogen following exercise. Int J Sport Nutr Exerc Metab 2001, 11:406-419.

14. Berardi JM, Noreen EE, Lemon PW: Recovery from a cycling time trial is enhanced with carbohydrate-protein supplementation vs. isoenergetic carbohydrate supplementation. J Int Soc Sports Nutr 2008, 24(5):24. 
15. Niles E, Lachowetz T, Garfi J, Sullivan W, Smith J, Leyh B, Headley S: Carbohydrate-protein drink improves time to exhaustion after recovery from endurance exercise. Journal of Exercise Physiology (Online) 2001, 4:45-52

16. Rowlands DS, Rössler K, Thorp RM, Graham DF, Timmons BW, Stannard SR, Tarnopolsky MA: Effect of dietary protein content during recovery from high-intensity cycling on subsequent performance and markers of stress, inflammation, and muscle damage in well-trained men. Appl Physiol Nutr Metab 2008, 33:39-51.

17. Skillen RA, Testa M, Applegate EA, Heiden EA, Fascetti AJ, Casazza GA: Effects of an amino acid-carbohydrate drink on exercise performance after consecutive-day exercise bouts. Int J Sport Nutr Exerc Metab 2008, 18:473-492.

18. Williams MB, Raven PB, Donovan L, Ivy JL: Effects of Recovery Beverages on Glycogen Restoration and Endurance Exercise Performance. $J$ Strength Cond Res 2003, 17:12-19.

19. Berardi JM, Price TB, Noreen EE, Lemon PWR: Postexercise muscle glycogen recovery enhanced with a carbohydrate-protein supplement. Med Sci Sports Exerc 2006, 38:1 106-1113.

20. Betts JA, Stevenson E, Williams C, Sheppard C, Grey E, Griffin J: Recovery of endurance running capacity: effect of carbohydrate-protein mixtures. Int J Sport Nutr Exerc Metab 2005, 15:590-609.

21. Betts JA, Williams C, Duffy K, Gunner F: The Influence of Carbohydrate and Protein Ingestion during Recovery from Prolonged Exercise on Subsequent Endurance Performance. J Sports Sci 2007, 25:1449-1460.

22. Karp JR, Johnston JD, Tecklenburg J, Mickelborough TD, Fly AD, Stager JM: Chocolate milk as a post-exercise recovery aid. Int J Sport Nutr Exerc Metab 2006, 16:78-91.

23. Thomas K, Morris P, Stevenson E: Improved endurance capacity following chocolate milk consumption compared with 2 commercially available sport drinks. Appl Physio/ Nutr Metab 2009, 34:78-82.

24. Cade JR, Reese RH, Privette RM, Hommen NM, Rogers JL, Fregley MJ: Dietary intervention and training in swimmers. Eur J Appl Physiol 1991, 63:210-215.

25. Leatt PB, Jacobs I: Effects of glucose polymer ingestion on muscle glycogen utilization during a soccer match. Canadian Journal of Sport Sciences 1989, 14:112-116.

26. Rico-Sanz J, Zehnder M, Buchli R, Dambach M, Boutellier URS: Muscle glycogen degradation during simulation of a fatiguing soccer match in elite soccer players examined noninvasively by 13C-MRS. Med Sci Sports Exerc 1999, 31:1587.

27. Twist $C$, Eston $R$ : The effects of exercise-induced muscle damage on maximal intensity intermittent exercise performance. Eur J Appl Physiol 2005, 94:652.

28. American College of Sports Medicine: Guidelines for Exercise Testing and Prescription Baltimore, Lippincott Williams \& Wilkins; 2006.

29. Lipsey MW: Design Sensitivity: Statistical Power for Experimental Research Newbury Park, CA: Sage Publications; 1990.

30. Saunders MJ, Moore RW, Kies AK, Luden ND, Pratt CA: Carbohydrate and protein hydrolysate co-ingestion improves late-exercise time-trial performance. Int J Sport Nutr Exerc Metab 2009, 19:136-149.

31. Kline CE, Durstine JL, Davis JM, Moore TA, Devlin TM, Zielinski MR, Youngstedt SD: Circadian variation in swim performance. J App/ Physiol 2007, 102:641-649.

32. Brown LE, Ferrigno V: Training for Speed, Agility and Quickness. In Training Drills for Peak Performance 2nd edition. Champaign, IL: Human Kinetics; 2005:79.

33. Byrne C, Eston R: The effect of exercise-induced muscle damage on isometric and dynamic knee extensor strength and vertical jump performance. J Sports Sci 2002, 20:417-425.

34. Jentjens R, Van Loon L, Mann C, Wagenmakers A, Jeukendrup AE: Addition of protein and amino acids to carbohydrates does not enhance postexercise muscle glycogen synthesis. J Appl Physiol 2001, 91:839-846

35. Van Loon LJ, Saris WHM, Kruijshoop M, Wagenmakers AJM: Maximizing postexercise muscle glycogen synthesis: carbohydrate supplementation and the application of amino acid or protein hydrolysate mixtures. Am J Clin Nutr 2000, 72:106-111.

36. Beaton $\sqcup$, Allan DA, Tarnopolsky MA, Tiidus PM, Phillips SM: Contractioninduced muscle damage is unaffected by vitamin E supplementation. Med Sci Sports Exerc 2002, 34:798-805.
37. Warren GL, Lowe DA, Armstrong RB: Measurement tools used in the study of eccentric contraction-induced injury. Sports Medicine 1999, 27:43-59.

38. Bird SP, Tarpenning KM, Marino FE: Liquid carbohydrate/essential amino acid ingestion during a short-term bout of resistance exercise suppresses myofibrillar protein degradation. Metabolism 2006, 55:570-7.

39. Achten J, Halson S, Moseley L, Rayson M, Casey A, Jeukendrup E: Higher dietary carbohydrate content during intensified running training results in better maintenance of performance and mood state. J App/ Physiol 2004, 96:1331-1340.

40. Burke LM, Kiens B, Ivy JL: Carbohydrates and fat for training and recovery. J Sports Sci 2004, 22:15-30.

\section{doi: $10.1186 / 1550-2783-7-19$}

Cite this article as: Gilson et al., Effects of chocolate milk consumption on markers of muscle recovery following soccer training: a randomized crossover study Journal of the International Society of Sports Nutrition 2010, 7:19

\section{Submit your next manuscript to BioMed Central and take full advantage of:}

- Convenient online submission

- Thorough peer review

- No space constraints or color figure charges

- Immediate publication on acceptance

- Inclusion in PubMed, CAS, Scopus and Google Scholar

- Research which is freely available for redistribution

Submit your manuscript at www.biomedcentral.com/submit
C) Biomed Central 